Artigo original

Hegemonia - Revista Eletrônica de Relações Internacionais do Centro Universitário Unieuro

ISSN: $1809-1261$

UNIEURO, Brasília, número 15, 2015, pp. 93-116.

Recebido em: $13 / 3 / 2015$

Avaliado em:28/4/2015

Aprovado em: $18 / 5 / 2 \mathrm{C}$

\title{
Crime Organizado no Brasil: Relatos de um Policial Militar
}

Jacques Nogueira Araújo ${ }^{1}$ e Vicente Fonseca ${ }^{2}$

Resumo: O presente artigo científico de revisão buscou analisar as ações praticadas por organizações criminosas no Brasil, bem como estudar os conceitos de: sociedade de risco, inimigo do Estado e crime organizado. Além disso, faremos a distinção entre crime organizado e criminalidade de massa. Como também indicaremos o surgimento do crime organizado no Brasil e suas principais organizações criminosas, que são: o Comando Vermelho (CV) e o Primeiro Comando da Capital (PCC). Pretendemos com isso demonstrar a abrangência do crime organizado no Brasil e a gravidade dos fatos diante da atuação incompetente do Estado. Uma vez que estes criminosos, a cada dia, encontram novos mecanismos para burlar as legislações vigentes e permanecerem na prática de ações delituosas, impunes diante dos olhos da sociedade.

PALAVRAS CHAVE: Organização criminosa. Sociedade. Estado.

Summary: This scientific review article investigates the activities of organized crime in Brazil, as well as study the concepts of risk society, enemy of the state and organized crime. In addition, we will make the distinction between organized crime and volume crime. But also will indicate the rise of organized crime in Brazil and its main criminal organizations, which are: the Comando Vermelho (CV) and the First Command of the

1 Mestrando em Ciência Política do Centro Universitário Euro Americana.

2 Doutor em Ciência Política e docente do Centro Universitário Euro Americana. 
Artigo original

Hegemonia - Revista Eletrônica de Relações Internacionais do Centro Universitário Unieuro

ISSN: $1809-1261$

UNIEURO, Brasília, número 15, 2015, pp. 93-116.

Capital (PCC). We intend to demonstrate the extention of organized crime in Brazil and the gravity of the facts before the incompetent actions of the State. Since these criminals, every day, find new mechanisms to circumvent the existing laws and continue the practicing criminal acts, unpunished under the eyes of society.

KEYWORDS: Organized Crime. Society. State.

\section{INTRODUÇÃO}

As organizações criminosas, associações criminosas, quadrilha ou bando, em geral, conseguem se estruturar de maneira tão organizada que chegam a formar uma força paralela ao Estado. Muitas vezes, contam com ramificações em diversos segmentos da sociedade e do governo (autoridades corruptas dos mais diversos escalões do governo), o que acaba por vilipendiar o próprio estado democrático de direito.

Ao longo deste artigo serão compartilhadas percepções acerca de um tema polêmico baseadas nos conhecimentos adquiridos ao longo de dezoito anos na função de Oficial Combatente da Polícia Militar do Distrito Federal - PMDF e durante uma especialização em segurança pública realizada na Polícia Militar do Estado da Paraíba - PMPB no ano de 2012.

Esperamos com isso contribuir para novas discussões e estudos na área. Pois, o crime organizado é um dos maiores problemas de segurança pública do mundo. No Brasil são os grupos criminosos, como os de tráfico de drogas ou tráfico de armas, que, além de incrementar na sociedade diversos crimes de "colarinho branco", a exemplo dos crimes de lavagem de capital e 
Artigo original

Hegemonia - Revista Eletrônica de Relações Internacionais do Centro Universitário Unieuro

ISSN: $1809-1261$

UNIEURO, Brasília, número 15, 2015, pp. 93-116.

corrupção, desenvolvem, igualmente, uma série de outros delitos, como roubos (para comprar drogas) e homicídios (por rixas entre traficantes).

Com vistas aos enormes problemas de segurança pública que os grupos criminosos causam à sociedade, devido as suas ramificações e fomento de diversos outros crimes, analisaremos, neste trabalho os conceitos como: sociedade de risco, inimigo do Estado e crime organizado. Apresentando a distinção entre este e a criminalidade de massa.

Além disso, iremos estudar as características do crime organizado e o surgimento do crime organizado no Brasil e suas principais Organizações criminosas, quais sejam: o Comando Vermelho (CV) e o Primeiro Comando da Capital (PCC). Pretendemos, com isso, demonstrar a abrangência do crime organizado no Brasil e a gravidade dos fatos, diante da atuação incompetente do Estado.

\section{CRIME ORGANIZADO}

\subsection{SOCIEDADE CONTEMPORÂNEA E CRIME ORGANIZADO}

De acordo com Giorgi (1998) na esteira das transformações que nos levaram à sociedade moderna, surge a noção do uso do monopólio da força pelo Estado e os atuais sistemas de governo. Nasce a democracia e o Estado Democrático de Direito, onde se estabele uma relação entre o Estado e a sociedade, caucada em obrigações e direitos. E a continuidade do processo evolutivo nos leva à sociedade contemporânea. 
Artigo original

Hegemonia - Revista Eletrônica de Relações Internacionais do Centro Universitário Unieuro

ISSN: $1809-1261$

UNIEURO, Brasília, número 15, 2015, pp. 93-116.

Por outro lado Giddens (1996, p. 72) afirmava que "o que caracteriza a modernidade são o dinamismo e o impacto global". Dessa forma, o desgaste dos costumes locais é fato na modernidade. A volubilidade e a liberdade dos indivíduos são muito maiores do que as dos indivíduos da sociedade antiga. A economia monetária, a moda, o individualismo, a liberdade e o consumismo são características indissociáveis da modernidade. O dinheiro passa, assim, de meio a fim absoluto, o senhor dos senhores, garantidor dos anseios de paz e de segurança.

Os riscos causados pelos avanços tecnológicos, da ciência e da cultura, pela relativização da noção de tempo e espaço e pela invisibilidade social, são elementos da modernidade, que é marcada pela indeterminação e pela instabilidade geradas pela falta de segurança e pela possibilidade do dano em razão das ações humanas.

Nessa realidade, Martins (2007) afirma que o Direito tenta assumir posição de provedor da segurança perdida na contemporaneidade. A questão da insegurança não é apenas social, mas, também jurídica, relacionando-se com a regulamentação de condutas (tarefa atribuída ao Direito pelo Estado). A conduta é a expressão do agir humano fundado na livre escolha e livrearbítrio.

O sentimento de insegurança, diante das ameaças e dos perigos, 0 sensacionalismo da mídia e sua capacidade de ufanar em demasia as ações criminosas, conduzem ao pânico social. Passa-se a falar do crime organizado sem que se saiba ao certo o que é e quem o produz. Sabe-se que é 
Artigo original

Hegemonia - Revista Eletrônica de Relações Internacionais do Centro Universitário Unieuro

ISSN: $1809-1261$

UNIEURO, Brasília, número 15, 2015, pp. 93-116.

altamente explosivo, todavia, passa-se a imagem de que é capaz de devorar a humanidade.

Evidentemente que não se pretende descaracterizar a gravidade e a importância dos fatos mencionados, apenas contextualizar como a disseminação reiterada pode fazê-lo assumir dimensão maior do que se apresenta. A vida em sociedade nos impõe riscos. Não é razoável acreditar na possibilidade de eliminação total dos riscos. Minimizar os riscos e construir uma sociedade em que seus níveis sejam satisfatórios é o grande desafio das gerações futuras.

Diante do exposto concordamos com a teoria de Baltazar Junior (2010), quando ele afirma que não é possível chegar a uma situação de inexistência de risco. Por exemplo, apesar dos riscos envolvidos, não se poderia defender a abolição do uso de automóveis, aeronaves, energia elétrica, ou mesmo armas de fogo. São casos de riscos socialmente aceitos, considerando o proveito da utilização de tais meios tecnológicos.

Assim, também em relação aos riscos decorrentes do crime, não se pode ter uma vigilância total de todos os cidadãos, com a finalidade de uma hipotética anulação dos delitos, pois, com isso, haveria uma inaceitável anulação da liberdade. Também, dessa forma, concordamos com a sociedade de riscos, desde que tenhamos garantido direitos fundamentais, como a liberdade, a vida e a segurança.

De acordo com Martins (2007), Günther Jakobs desenvolveu uma teoria que, uma vez aplicada, poderia colocar em xeque garantias e direitos fundamentais. Para ele, o direito penal teria duas faces. A primeira seria o 
Artigo original

Hegemonia - Revista Eletrônica de Relações Internacionais do Centro Universitário Unieuro

ISSN: $1809-1261$

UNIEURO, Brasília, número 15, 2015, pp. 93-116.

direito penal do cidadão aplicado ao criminoso comum, que com sua conduta promoveu uma desautorização da norma, mas que, por não perder sua condição de cidadão, deveria ser processado segundo os ditames constitucionais. A segunda seria o direito penal do inimigo, que puniria os indivíduos considerados mais perigosos para a sociedade, a exemplo dos terroristas. Nessa situação, o Estado estaria legitimado a suprimir direitos e garantias individuais, pois o criminoso não mais seria tido como cidadão.

Gomes (2004) nos explica de maneira clara como os fundamentos filosóficos do Direito Penal do Inimigo estão alicerçados no pensamento dos contratualistas e, portanto, na quebra do pacto e conseqüente afronta ao Estado:

Para Rousseau: "o inimigo, ao infringir o contrato social, deixa de ser membro do Estado, está em guerra contra ele, logo, deve morrer como tal". Enquanto Hobbes: compreende que: "em casos de alta traição contra o Estado, o criminoso não deve ser castigado como súdito, senão como inimigo". (GOMES, 2004, p.1).

Nesse ponto, encaixa-se o pensamento de Foucault (1987), pois, segundo o autor, a pena para ser útil deve ser calculada não em função do delito, mas de possível reincidência. Visa não à ofensa passada, mas à desordem futura. Os efeitos futuros da pena fazem com que o criminoso não 
Artigo original

Hegemonia - Revista Eletrônica de Relações Internacionais do Centro Universitário Unieuro

ISSN: $1809-1261$

UNIEURO, Brasília, número 15, 2015, pp. 93-116.

possa ter vontade de recomeçar. A denominada arte de punir é, portanto, tornar desvantajosa a ideia da prática do delito.

Entendemos, diante do exposto, que o conceito de Direito Penal do Inimigo pode ser aperfeiçoado, para se adequar à realidade brasileira e, desta forma, assegurar as garantias processuais. Entretanto, a execução penal pode ser distinta, ou seja, o criminoso comum, depois de apenado, estaria sujeito à Lei de Execução Penal tida como comum e, ao inimigo do Estado, a sujeição a outras regras de execução penal capazes de Ihes tirar a periculosidade. Sugerimos uma lei de execução penal de exceção, ou, de forma mais simplista, tratamento desigual para os desiguais.

Acreditamos que, no Brasil, o Direito Penal do Inimigo pode ser perfeitamente utilizado, desde que adequado ao nosso ordenamento jurídico, pois o Estado precisa sobreviver. Diante da discussão, Bobbio (1986) nos ensina que o Estado, como todo ser vivo, antes de se deixar matar, deve se defender. Ele nasce da força e só pode sobreviver da força. Portanto, aquele que sobrevive através da força é de fato reverenciado como Estado. Nesse mundo, ou o Estado é a maior concentração de força legítima existente num determinado território ou não é Estado.

A partir de agora iremos procurar uma definição técnica do que seja crime organizado, delimitando seus conceitos, bem como as circunstâncias que determinam sua ocorrência. Nesse sentido, Martins (2007) define uma organização como um grupo de pessoas, um grupo social, com objetivos próprios e dissociados da vontade geral da sociedade como um todo. A constituição da organização decorre da assunção das 
Artigo original

Hegemonia - Revista Eletrônica de Relações Internacionais do Centro Universitário Unieuro

ISSN: $1809-1261$

UNIEURO, Brasília, número 15, 2015, pp. 93-116.

vontades individuais voltadas para a consecução de metas específicas, através de prévia distribuição dos membros em uma estrutura hierárquica.

De acordo com o sociólogo e investigador da Polícia Civil de São Paulo, Mingardi (1998, p.178), "[...] o crime organizado caracteriza-se pela previsão de lucros, hierarquia, planejamento empresarial, divisão de trabalho, simbiose com o Estado, pautas de conduta estabelecida em códigos, procedimentos rígidos e divisão territorial".

Contudo, até a publicação da Lei no 12.694, de 24 de julho de 2012, a qual dispõe sobre o processo e o julgamento colegiado em primeiro grau de jurisdição de crimes praticados por organizações criminosas, prevalecia na jurisprudência pátria que não havia no Brasil consenso para o conceito a ser adotado para organização criminosa e, portanto, não se poderia aplicar referidos meios investigativos a esses grupos.

Assim, com a promulgação da Lei no 12.694/2012, temos, no seu artigo $2^{\circ}$, a definição de organização criminosa com a seguinte redação:

Para os efeitos desta Lei, considera-se organização criminosa a associação, de 3 (três) ou mais pessoas, estruturalmente ordenada e caracterizada pela divisão de tarefas, ainda que informalmente, com objetivo de obter, direta ou indiretamente, vantagem de qualquer natureza, mediante a prática de crimes cuja pena máxima seja igual ou superior a 4 (quatro) anos ou que sejam de caráter transnacional. (BRASIL, 2012). 
Artigo original

Hegemonia - Revista Eletrônica de Relações Internacionais do Centro Universitário Unieuro

ISSN: $1809-1261$

UNIEURO, Brasília, número 15, 2015, pp. 93-116.

Nota-se a dificuldade de encontrarmos uma definição capaz de sintetizar com precisão o que seja crime organizado. O fato é que a criminalidade moderna, representada pelas organizações criminosas, não pode ser analisada de forma isolada. Não podemos pensar que as organizações criminosas é somente um fenômeno da sociedade contemporânea, mas sim o resultado de um processo evolutivo das sociedades.

Dessa maneira, $O$ Direito Penal precisa encontrar sua correspondência com o fenômeno social. Portanto, o crime organizado, fenômeno criminológico, deve ser visto de forma harmônica com a perplexidade da contemporaneidade.

Podemos deduzir que qualquer legislação a respeito do tema precisa atentar para as características próprias do crime organizado na época atual e em consonância com as características e necessidades dos grupos sociais. Exige-se uma legislação com base nos fatos presentes e que seja voltada para a solução dos problemas futuros.

Há uma grande confusão entre os campos de incidência da criminalidade e, portanto, torna-se necessário distinguirmos crime organizado (ou criminalidade organizada) e criminalidade de massa. Uma forma de fazê-lo é analisar seus efeitos e conseqüências para a sociedade. A decorrente das massas atinge a sociedade diretamente. São cotidianas essas práticas criminosas, possuem vítimas mediatas, as quais podem ser identificadas, assim como os meios de ação criminosos. 
Artigo original

Hegemonia - Revista Eletrônica de Relações Internacionais do Centro Universitário Unieuro

ISSN: $1809-1261$

UNIEURO, Brasília, número 15, 2015, pp. 93-116.

Enquanto a criminalidade organizada é um fenômeno cambiante, constituído em uma gama de infrações penais sem vítimas imediatas ou com vítimas difusas. Possui campos férteis em seu país e múltiplos meios de disfarce e simulação.

Para Hassemer (1994), a criminalidade organizada é menos visível que a criminalidade de massas, sendo que os especialistas ainda não conseguem chegar a um consenso sobre no que ela realmente consiste. Discordamos do autor e defendemos o ponto de vista de Baltazar Junior (2010) quando afirma que a criminalidade organizada pode ser entendida como uma modalidade de criminalidade profissional, porém, bastante visível para a sociedade.

Baltazar Junior (2010) define a criminalidade de massas como aquela tão corriqueira que os fatos que a constituem não são sequer noticiados ou investigados, tais como furtos de rua ou em residências, pequeno tráfico de drogas. Para o referido autor, tais crimes atingiriam de forma muito mais aguda o cidadão; e a omissão do Estado, em relação ao combate de tal modalidade criminosa, é que causaria a sensação de insegurança e dúvidas quanto ao funcionamento do Estado.

Concordamos com Baltazar Junior (2010), pois se o cidadão não é atendido em relação às pequenas demandas criminosas, como pequenos furtos na rua, ele simplesmente passa a duvidar do dever de proteção do Estado. Sendo assim, podemos evidenciar que é a banalização dos pequenos crimes que aumenta a sensação de insegurança das pessoas.

\subsection{CARACTERÍSTICAS DAS ORGANIZAÇÕES CRIMINOSAS}


Artigo original

Hegemonia - Revista Eletrônica de Relações Internacionais do Centro Universitário Unieuro

ISSN: $1809-1261$

UNIEURO, Brasília, número 15, 2015, pp. 93-116.

Seguindo a linha de pensamento de Baltazar Junior (2010), acreditamos que apesar da falta de consenso dos doutrinadores sobre o conceito de crime organizado, é possível elencar as principais características reconhecidas na jurisprudência.

Desta forma, iremos apontar como características essenciais as compatíveis com a Convenção de Palermo, a qual foi profundamente estudada por Capez (2010), que entende ser este o documento do qual devemos extrair o conceito de organização criminosa. Vejamos o que diz o artigo $2^{\circ}$ da Convenção:

Artigo $2^{\circ}$ - Grupo estruturado de três ou mais pessoas, existente há algum tempo e atuando concertadamente com o propósito de cometer uma ou mais infrações graves ou enunciadas na presente Convenção, com a intenção de obter, direta ou indiretamente, um benefício econômico ou outro benefício material. (CAPEZ, 2010, p.135).

Acompanhando os autores, ficamos cientes de que existem outras características não essenciais, tais como hierarquia, divisão de trabalho, especialização, logística, utilização de meios tecnológicos, o uso da compartimentalização, da corrupção, da destruição de provas e da intimidação de testemunhas. Todas são importantes para a caracterização das organizações criminosas. Contudo, no momento apontaremos somente as características essenciais de todas as organizações criminosas, vejamos as seguintes: 
Artigo original

Hegemonia - Revista Eletrônica de Relações Internacionais do Centro Universitário Unieuro

ISSN: $1809-1261$

UNIEURO, Brasília, número 15, 2015, pp. 93-116.

a) Pluralidade de agentes

A ideia de organização traduz a presença de uma coletividade. Assim, fica claro que não se concebe uma organização individual. Na Convenção de Palermo, exige-se um mínimo de três pessoas, sendo a pluralidade de agentes reconhecida em todos os países que adotam a Convenção.

b) Estabilidade ou permanência

$\mathrm{Na}$ ideia de organização, a permanência ou estabilidade são fundamentais para diferenciar a organização criminosa do mero concurso eventual de agentes. A Convenção de Palermo, em seu artigo ${ }^{\circ}$, considera como "grupo criminoso organizado aquele existente há algum tempo e atuando concertadamente com o propósito de cometer uma ou mais infrações graves". (BALTAZAR JUNIOR, 2010, p.124).

Caso o grupo não se perpetue, em razão da ocorrência da mera reunião de agentes com o fim de cometer crimes, não há que se falar em grupo criminoso organizado e sim no crime de quadrilha.

c) Finalidade de lucro

O chamado crime negócio, ou o "fim lucrativo" é um ponto onde os doutrinadores concordam plenamente. $O$ artigo $2^{\circ}$ da Convenção de Palermo deixa claro: "a intenção de obter, direta ou indiretamente, um benefício econômico ou outro benefício material". (CAPEZ, 2010, p.135).

Para Mingardi (apud BALTAZAR JUNIOR, 2010), mais que mero fim de lucro, o crime organizado é marcado pela previsão de lucro, possibilitada pela regularidade da atuação criminosa. Aqui temos a distinção da organização do ladrão que simplesmente toma o que puder em cada roubo cometido. 
Artigo original

Hegemonia - Revista Eletrônica de Relações Internacionais do Centro Universitário Unieuro

ISSN: $1809-1261$

UNIEURO, Brasília, número 15, 2015, pp. 93-116.

d) Organização

A adoção de estruturas empresariais é compatível com a finalidade das atividades criminosas que é o lucro. Assim, há uma profissionalização da atividade criminosa, que é planejada, de modo sistemático, e adotada como meio de vida.

Segundo Baltazar Junior (2010), o grau de organização é variável e, do ponto de vista legal, deve ser tratado como elemento normativo do tipo, a ser verificado no caso concreto, cabendo à jurisprudência o papel de atribuir maior clareza a esse tipo de característica.

Observando todas as características das organizações criminosas, verificamos que o paradigma empresarial capitalista, como motor da vida econômica mundial, não poderia deixar de ter reflexos na criminalidade. Nessa medida, Baltazar Junior (2010) enfatiza que as organizações criminosas assemelham-se às empresas lícitas, das quais se distinguem por utilizar métodos ilícitos, enquanto nas primeiras são utilizados, predominantemente, métodos lícitos.

\subsection{O SURGIMENTO DO CRIME ORGANIZADO NO BRASIL}

No Brasil, temos um campo fértil para o crime organizado, o qual se dá por meio da corrupção, que promove uma conexão estreita do crime com o poder público. Assis (2009) afirma que o País é refúgio ideal para mafiosos de alto nível; e interessante praça de lavagem de dinheiro e caminho para o tráfico internacional de drogas.

De acordo com Assis (2009), as atividades criminosas mais praticadas pelo crime organizado no Brasil são as seguintes: tráfico de 
Artigo original

Hegemonia - Revista Eletrônica de Relações Internacionais do Centro Universitário Unieuro

ISSN: $1809-1261$

UNIEURO, Brasília, número 15, 2015, pp. 93-116.

drogas; contrabando de armas; lavagem de dinheiro; expedição de documentos falsos; extorsão de pessoas ou empresas; tráfico de órgãos humanos e também de seres humanos; evasão de divisas e sonegação fiscal; e outros favorecimentos ilegais que giram em torno da corrupção. Todavia, entendemos que essas atividades têm caráter meramente explicativo, na medida em que se torna muito difícil sistematizar o universo de condutas típicas dessas organizações criminosas.

O que pretendemos demonstrar é que não podemos negar a existência do crime organizado no Brasil, apesar das dificuldades na identificação de todas as suas atividades criminosas. Amorim (2011) revela que a atividade ilegal está globalizada e o país é um mercado privilegiado para a atuação de grupos criminosos.

Infelizmente, não estamos preparados para enfrentar o crescimento da violência urbana e do crime organizado. Concordamos plenamente com Amorim (2011), pois nossas polícias precisam de treinamento, equipamento adequado e salários capazes de frear a corrupção. E temos ainda o peso de um Código Penal de 1940, o qual se encontra totalmente desatualizado.

Nossas leis não estão adequadas a um país onde a televisão mostra que as favelas e bairros pobres são dominados por bandos armados até com metralhadoras antiaéreas e foguetes. Enquanto isso, nossas polícias, de acordo com Soares (2006), são máquinas pesadas e lentas, nada inteligentes e criativas, que não valorizam seus policiais nem os preparam adequadamente.

Conforme Mingardi (apud, BALTAZAR JUNIOR, 2010), no Brasil, as organizações criminosas mais conhecidas são as facções conhecidas como: 
Artigo original

Hegemonia - Revista Eletrônica de Relações Internacionais do Centro Universitário Unieuro

ISSN: $1809-1261$

UNIEURO, Brasília, número 15, 2015, pp. 93-116.

Comando Vermelho (CV) e o Primeiro Comando da Capital (PCC). Acreditamos que essas organizações criminosas, aliadas à corrupção estatal no Brasil, representam um grave problema para a segurança pública e, por isso, vamos trazer mais esclarecimentos sobre elas no próximo capítulo deste trabalho.

De acordo com Amorim (2011), o marco da instalação do crime organizado no Brasil ocorre com a fundação do Comando Vermelho, nos porões do presídio da Ilha Grande, no Estado do Rio de Janeiro. A criação da facção, entre os anos de 1974 e 1979, de acordo com o autor, é fruto do convívio entre presos comuns e militantes dos grupos armados que combatiam o regime militar.

Concordamos com Amorim (2011), pois o Comando Vermelho surge inicialmente por meio de reivindicações justas de um grupo de homens oprimidos por um sistema carcerário violento e corrupto com o lema "Paz, Justiça e Liberdade", contudo, a força capitalista do tráfico de drogas se institucionalizou e o lema verdadeiro por trás do mito passou a ser "tudo por dinheiro".

De acordo com levantamentos realizados por Amorim (2011), os principais fundadores do Comando Vermelho foram: William da Silva Lima, o professor; Paulo César Chaves, o PC Branco; José Jorge Saldanha, o Zé do Bigode; Francisco Viriato de Oliveira, o japonês; e Rogério Lemgruber, o Bagulhão. Esses homens formaram o primeiro núcleo da organização. Contudo, ao longo dos anos, outros criminosos foram sendo incorporados e substituindo os mais velhos no comando da facção.

Consideramos o dia 03 de abril de 1981 o primeiro grande momento midiático do Comando Vermelho. De acordo com Amorim (2011), 
Artigo original

Hegemonia - Revista Eletrônica de Relações Internacionais do Centro Universitário Unieuro

ISSN: $1809-1261$

UNIEURO, Brasília, número 15, 2015, pp. 93-116.

no conjunto dos Bancários da Ilha do Governador - Rio de Janeiro -, José Jorge Saldanha (o Zé do Bigode), um dos fundadores do Comando Vermelho, foi cercado pela polícia carioca no apartamento onde morava, reagiu, atirando. O tiroteio com a polícia, o qual durou aproximadamente 12 horas de resistência de um criminoso contra quatrocentos policiais, teve como saldo de combate cinco mortos, oito feridos graves e dezesseis sem gravidade.

A atuação desarticulada da polícia durante o tiroteio nos revela a incapacidade operacional e a inexistência de um plano tático a ser empregado nesse tipo de situação. O problema disso tudo é que, após trinta e três anos a polícia ainda está marcando passo, enquanto o crime organizado evolui a cada dia.

O tráfico de drogas é sem dúvida o responsável pela grande ampliação do poder do Comando Vermelho. Segundo Amorim (2011), a partir dos anos 80, o Brasil entrou definitivamente na rota do tráfico internacional de drogas, como ponto de distribuição para a Europa e como mercado consumidor do produto de baixa qualidade.

De acordo com o estudioso, a associação inicial foi feita com traficantes bolivianos e, posteriormente, com as Forças Armadas Revolucionárias da Colômbia (FARC), tendo como principal mentor do lado brasileiro o traficante Luiz Fernando da Costa, conhecido como "Fernandinho Beira-Mar", o menino pobre da favela que acabou se transformando no maior traficante brasileiro.

Amorim (2011) revela que Fernandinho Beira-Mar, antes de ser preso movimentava aproximadamente 70 milhões de reais por mês com o tráfico internacional de drogas. E ainda tem atividades ilícitas no Rio de 
Artigo original

Hegemonia - Revista Eletrônica de Relações Internacionais do Centro Universitário Unieuro

ISSN: $1809-1261$

UNIEURO, Brasília, número 15, 2015, pp. 93-116.

Janeiro, São Paulo, Paraná, Mato Grosso do Sul e Paraíba. Em um ano, o faturamento atinge aproximadamente 840 milhões de reais. O negócio com as FARC baseia-se na troca de mercadorias, armas e drogas e pagamento em dinheiro, conforme o caso.

O tráfico de drogas, desenvolvido pelo crime organizado, também trouxe consigo armamento pesado, como pistolas calibre $7,65 \mathrm{~mm}$, fuzis automáticos, granadas, rifles, miras especiais de laser, munição de aço especial, armamento de guerra antitanque e antiaéreo. Segundo Amorim (2011), em maio de 2002, foi apreendido, pela polícia militar do Rio de Janeiro, um fuzil austríaco Steyr, considerado a arma de infantaria mais moderna do mundo.

De acordo com Soares (2006), o tráfico de drogas é responsável pelo aumento da violência, em especial na elevação da taxa de homicídios entre jovens de 18 a 24 anos. A taxa de homicídios (mortes por 100 mil habitantes) no Rio de Janeiro é de 57,2. Quando analisamos a mencionada faixa etária, sobe para 102,8 mortes. O autor revela ainda que mais de 40 mil pessoas são assassinadas todos os anos em nosso país.

Amorim (2011) estima que 10.500 homens façam parte do Comando Vermelho, que controla 108 favelas e bairros populares no Rio de Janeiro. Contudo, aos poucos, o CV foi ampliando sua atuação para outras partes do país. A organização chegou a São Paulo no início da década de 90, no conjunto habitacional Cidade Tiradentes (zona leste), injetando armamento e dinheiro e associando-se ao tráfico e aos grandes nomes do jogo do bicho.

O sucesso do Comando Vermelho no mundo do crime fomentou a criação de novas organizações criminosas, dentre elas vamos citar a mais 
Artigo original

Hegemonia - Revista Eletrônica de Relações Internacionais do Centro Universitário Unieuro

ISSN: $1809-1261$

UNIEURO, Brasília, número 15, 2015, pp. 93-116.

famosa: o Primeiro Comando da Capital (PCC). O qual, de acordo com Amorim (2011), foi criado em 1993, pelos presos da Casa de Custódia de Taubaté (interior de São Paulo). Seus líderes viviam da extorsão de detentos nos presídios e exigiam dinheiro em troca de proteção. Quem não colaborava era jurado de morte. Nesse período, o PCC se especializou em promover motins para pressionar o Governo, com o objetivo de obter regalias.

No dia 18 de fevereiro de 2001, o PCC coordenou uma revolta de presos em praticamente todo o Estado de São Paulo. Amorim (2011) afirma que a principal arma dos presos era o telefone celular, introduzido nas celas com a conivência dos agentes penitenciários. A rebelião mobilizou aproximadamente mais de 27 mil presos e revelou que a organização criminosa havia conquistado a massa carcerária paulista.

Dezesseis integrantes das facções rivais foram mortos e, a partir desse evento, Amorim (2011) nos revela que o PCC cresceu ainda mais como organização criminosa e ampliou suas atividades. Atualmente, o mundo criminoso do PCC é eclético, sendo suas ações ditadas pelo oportunismo, tais como: o tráfico de drogas, dentro e fora dos presídios, que é a sua atividade mais lucrativa. Contudo, atua também em roubos e furtos a bancos; roubos a empresas de transporte de valores e seqüestros.

Semelhante ao que ocorreu no Estado do Rio de Janeiro, quando o Comando Vermelho surgiu, a cúpula da Segurança Pública de São Paulo ignorou o surgimento do PCC, fato comprovado por Amorim (2011, p. 388), que nos revela que pessoas ligadas ao sistema penal paulista escreveram relatórios sobre o surgimento da organização, os quais foram ignorados e, por isso, temos de conviver com mais um problema crônico de segurança no 
Artigo original

Hegemonia - Revista Eletrônica de Relações Internacionais do Centro Universitário Unieuro

ISSN: $1809-1261$

UNIEURO, Brasília, número 15, 2015, pp. 93-116.

país. Vejamos a descrição de Amorim (2011, p. 375) da narrativa da repórter Fátima de Souza:

[...] nas rebeliões, lençóis brancos apareciam com as três letras (PCC) do partido do crime. Subestimado pelo governo, que não conhece a realidade das cadeias, o PCC criou raízes em todo o sistema carcerário paulista. Nas prisões, diretores ultrapassados, da época da repressão [no regime militar], tentavam resolver o problema da maneira em que foram doutrinados: porretes, choques, água fria, porrada... Não foi suficiente. Em menos de três anos, já eram três mil. Em menos de dez anos, 40 mil [...]. (FÁTIMA DE SOUZA apud AMORIM, 2011, p.375).

De acordo com Amorim (2011), o crescimento acelerado do PCC demonstra que o grande poder de sedução da massa carcerária, que se encontra em grau máximo de desesperança, está justamente na capacidade de ressuscitar a esperança. O PCC vende ilusões.

Conforme o estudioso, as principais lideranças do PCC encontramse presas e sua força emana de dentro dos presídios. Essa organização criminosa é a maior em atividade no Brasil e estima-se que conte com 15 mil integrantes. O crescimento da organização ocorre em razão do vácuo deixado pelo poder público, visto que a polícia paulista tem cadastrados algo em torno de seis mil integrantes.

De acordo com Martins (2007), levantamentos feitos pelo Conselho de Controle de Atividades Financeiras (COAF), com base nas investigações da polícia e do Ministério Público de São Paulo, mostram que 260 pessoas 
Artigo original

Hegemonia - Revista Eletrônica de Relações Internacionais do Centro Universitário Unieuro

ISSN: $1809-1261$

UNIEURO, Brasília, número 15, 2015, pp. 93-116.

ligadas ao PCC movimentaram 232 contas bancárias, totalizando $R \$ 36,6$ milhões no período de um ano.

Concordamos com Amorim (2011) quando afirma que o criminoso é um exemplo do extrato social, entre aqueles que esperam alguma ascensão e aqueles outros que não esperam mais nada. O Estado se omite e a polícia mais uma vez é usada como massa de manobra, pois os verdadeiros criminosos estão protegidos pelo manto dos poderes: executivo, legislativo e judiciário.

A verdade é que, para os barões mundiais do tráfico, bandido da favela não tem muita relevância, pois o que importa são os grandes lucros que o crime organizado movimenta. Segundo Amorim (2011), os números globais do tráfico estão entre 600 e 800 bilhões de dólares a cada ano.

Os nossos chefes do crime organizado são fichas pequenas no mundo dos narcóticos. Comandam a distribuição no varejo das drogas, mas não sabem quem são os seus patrões. Amorim (2011) nos alerta para o desemprego que atinge 12 milhões de trabalhadores qualificados. Com essa população desempregada não temos como evitar que muitos desses trabalhadores ingressem no tráfico de drogas, que é uma das atividades mais rentáveis do planeta.

\section{CONSIDERAÇÕES FINAIS}

Ao longo de nosso trabalho o que ficou constatado é que o cidadão 
Artigo original

Hegemonia - Revista Eletrônica de Relações Internacionais do Centro Universitário Unieuro

ISSN: $1809-1261$

UNIEURO, Brasília, número 15, 2015, pp. 93-116.

no Brasil está sendo duplamente enganado, pois paga impostos e não tem a segurança devida, além disso, as autoridades escamoteiam a verdade, pois insistem em negar a existência do crime organizado no País, fato que é uma realidade diante da nossa pesquisa. Acreditamos ainda que a omissão do Estado em não assumir o seu papel de mantenedor da Ordem Pública, acarreta um descrédito perante a sociedade o que coloca em cheque a legitimação do Estado.

A Lei Penal no Brasil é apenas um paliativo na questão do avanço das organizações criminosas, pois a evolução contínua do Crime Organizado se deve a mais completa ausência de políticas de controle da criminalidade, associado à miséria em que vive boa parte da população brasileira. Assim, perante a população mais carente, O Estado não ocupou o seu lugar e paga caro por sua omissão.

Todavia, perante a parcela da sociedade mais abastada o Crime Organizado surge como forma de aumentar ainda mais suas riquezas e seu poder. Estamos diante de um câncer no seio da sociedade, vez que corrompe todos os segmentos em todas as esferas de poder. Em suma, a violência e a corrupção andam juntas, pois a impunidade está em todos os meios, e o péssimo exemplo emanado das altas esferas da vida pública corrompem os aparelhos de Segurança Pública no Brasil.

\section{REFERÊNCIAS BIBLIOGRÁFICAS}

AMORIM, Carlos. CV-PCC: a irmandade do crime. Rio de Janeiro: Record, 2011. 
Artigo original

Hegemonia - Revista Eletrônica de Relações Internacionais do Centro Universitário Unieuro

ISSN: $1809-1261$

UNIEURO, Brasília, número 15, 2015, pp. 93-116.

ASSIS, Normando de. A Problemática do Crime Organizado e a Legislação Vigente no País. Brasília: Curso de Altos Estudos de Oficiais. Academia de Polícia Militar de Brasília, 2009.

BALTAZAR JUNIOR, José Paulo. Crime Organizado e proibição de insuficiência. Porto Alegre: Livraria do Advogado, 2010.

BOBBIO, Norberto. As ideologias e o poder em crise. 4. ed. Brasília: Editora da UNB, 1999.

. Direito e Estado no pensamento de Immanuel Kant. São Paulo: Mandarim, 1986.

BRASIL. Constituição da República Federativa do Brasil/1988. São Paulo: Imprensa Oficial do Estado de São Paulo, 2011.

Lei no 12.694/12. Disponível em:

<http://www.planalto.gov.br/ccivil_03/_ato2011-

2014/2012/lei/l12694.htm> Acesso em: 29 out. 2012.

CAPEZ, Fernando. Curso de direito penal: Legislação Penal Especial. v. 4. 5. ed. São Paulo: Saraiva, 2010.

CRUZ, Elaine Patrícia da. Notícias: Agência Brasil. 2012. Disponível em: < http://br.noticias.yahoo.com/desde-janeiro-80-policiais-foram-mortos-spconfirma-pm.html > Acesso em 29 out.2012.

FOUCAULT, Michel. Vigiar e punir. 32. ed. Petrópolis: Vozes, 1987.

GIDDENS, Anthony. As conseqüências da modernidade. São Paulo: UNESP, 1991.

. Modernidad y autoidentidad. Barcelona, 1996.

GIORGI, Raffaele de. Direito, democracia e risco: vínculos com o futuro. Porto Alegre: Fabris, 1998. 
Artigo original

Hegemonia - Revista Eletrônica de Relações Internacionais do Centro Universitário Unieuro

ISSN: $1809-1261$

UNIEURO, Brasília, número 15, 2015, pp. 93-116.

GOMES, Luiz Flávio. Legislação penal especial. In: Revista dos Tribunais. v. 6. São Paulo, 2009.

- Organização Criminosa e Convenção de Palermo. Disponível em: <http://www.Ifg.com.br/public_html/article.php?story=201102212133 13636\& mode $=$ print $>$. Acesso em 24 set. 2012.

_. Direito Penal do Inimigo. 2004. Disponível em: <http://www.Ifg.com.br/public_html/article.php?story=200409271139 55798\&. Acesso em 08 out. 2012.

HASSEMER, Wilfried. Perspectivas de uma moderna política criminal. São Paulo: Revista Brasileira de Ciências Criminais, número 8, 1994.

. Três temas de direito penal. In: GOMES, Luiz Flávio; CERVINI, Raúl.

Crime organizado: enfoques criminológico, jurídico (Lei 9.034/95) e político-criminal. 2. ed. São Paulo: RT, 1997.

HOBBES, Thomas. Textos escolhidos. 3. ed. São Paulo: Abril Cultural, 1986.

JAKOBS, Gunther. Revista de Ciência Penal n. 97. Madrid, 1985.

JAKOBS, Gunther; CANCIO MELIÁ, Manuel. Direito Penal do inimigo. Tradução de André Luis Callegari e Nereu José Giacomolli. São Paulo: Livraria do Advogado, 2005.

LOCKE, John. Textos escolhidos. 3. ed. São Paulo: Abril Cultural, 1986.

MARTINS, Allan. A atuação do crime organizado no sistema prisional e a importância do trabalho de inteligência policial. São Paulo: Curso de Aperfeiçoamento de Oficiais. Centro de Aperfeiçoamento e Estudos Superiores, 2007.

MINGARDI, Guaracy. O Estado e o crime organizado. São Paulo: IBCCrim, 1998. 
Artigo original

Hegemonia - Revista Eletrônica de Relações Internacionais do Centro Universitário Unieuro

ISSN: $1809-1261$

UNIEURO, Brasília, número 15, 2015, pp. 93-116.

ROSSEAU, Jean-Jacques. Textos escolhidos. 3. ed. São Paulo: Abril Cultural,1986.

SOARES, Luiz Eduardo. Segurança pública: presente e futuro. 2006. Disponível em: http://www.scielo.br/pdf/ea/v20n56/28629.pdf. Acesso em 28 jul. 2012. 